\title{
VIBRATIONS OF DRIVE SYSTEMS FLEXIBLE ELEMENTS AND METHODS OF DETERMINING THEIR OPTIMAL NONLINEAR CHARACTERISTICS BASED ON THE LAWS OF MOTION
}

\author{
B. I. Sokil, O. I. Khytriak
}

A method of solving inverse dynamics problems, which are described by nonlinear partial differential equations is developed. They contain mixed derivative linear and temporal variables and describe the oscillation in drive system flexible elements. It is based on the idea of presentation the process in the form of waves of different lengths, but the same frequency and on the generalizations on the basis of the asymptotic method of nonlinear mechanics to new classes of dynamical systems. This technique allows to specify the approximation of nonlinear elastic and the dissipation properties of the system, on the assumption of a given law of variation of the key motion parameters.

Keywords: nonlinear oscillation, amplitude, frequency, asymptotic method.

УДК 681.317 .39

\author{
Ю.В. Шабатура ${ }^{1}$, К.В. Овчинников ${ }^{2}$ Ю.В. Бугайов ${ }^{3}$ \\ ${ }^{1}$ Академія сухопутних військ ім. гетьмана П. Сагайдачного, Львів \\ ${ }^{2}$ Вінницький національний технічний університет, Вінниця \\ ${ }^{3}$ ТОВ «ІВП ІнноВіннпром», Вінниця
}

\section{УНІВЕРСАЛЬНИЙ ВИМІРЮВАЛЬНИЙ МОДУЛЬ ДЛЯ ПОБУДОВИ І МОДЕРНІЗАЦІЇ КОНТРОЛЬНО-ВИМІРЮВАЛЬНИХ СИСТЕМ ВІЙСЬКОВО-ТЕХНІЧНИХ КОМПЛЕКСІВ}

Виконана розробка математичного, метрологічного, технічного $і$ алгоритмічного забезпечення для побудови універсального вимірювального модуля, який функціонує на основі використання принцииу часового представлення вимірювальної інформачії. Проведені дослідження показали придатність розробленого модуля не лише для побудови нових засобів вимірювань але $і$ для модернізації застарілих вимірювальних приладів і систем. Застосування модуля дозволяє суттєво збільшити точність вимірювань $i$ завадостійкість з одночасним зменшенням енергоспоживання.

Ключові слова: імпульсні тестові сигнали, часове представлення вимірювальної інформації, часоцифрові перетворювачі, мостова, потенціометрична вимірювальна схема.

\section{Вступ}

Постановка проблеми. Сучасні засоби контрольно-вимірювальної техніки у відповідності 3 принципами свого функціонування обов'язково передбачають проведення вимірювань значень різних фізичних величин. Як правило процедури вимірювань в таких засобах проводяться 3 використанням у якості носіїв вимірювальної інформації електричних сигналів, отже за визначенням це $\epsilon$ електричні вимірювання. Сьогодні у зв'язку з зростанням складності і відповідальності технічних систем і технологій, які використовуються у військово-технічних комплексах, до засобів електричних вимірювань висуваються дуже жорсткі вимоги, які потребують водночас i суттєвого підвищення точності, і зменшення споживаної потужності, і покращення завадостійкості $[1,2]$. У сукупності це приводить до необхідності розробки нових, більш досконалих вимірювальних пристроїв, оскільки існуючі вже неспроможні задовольняти пред'явленим до них вимогам. Отже виникає гостра потреба в розробці універсального вимірювального модуля, який дозволяв би з одного боку створювати на його основі нові вимірювальні засоби, а з іншого боку був би придатний для модернізації застарілих вимірювальних приладів і систем.

Аналіз останніх досліджень і публікацій. Вирішенню задачі підвищення точності вимірювань, зменшення енергоспоживання в вимірювальних каналах і підвищення їх завадостійкості присвячено чимало публікацій [2-4]. Однак, лише в окремих 
роботах $[4,5]$ пропонуються принципово нові, по справжньому фундаментальні підходи, здатні забезпечити радикальне покращення метрологічних i експлуатаційних характеристик засобів вимірювань. Попередні дослідження показали, що на основі таких принципів доцільно розробити універсальний вимірювальний модуль придатний до інтеграції в різні засоби вимірювань, які використовуються у військово-технічних комплексах, що призведе до їх загального покращення.

Постановка задачі. Розробити універсальний вимірювальний модуль для побудови і модернізації контрольно вимірювальних систем військовотехнічних комплексів. Розробити математичне, метрологічне, алгоритмічне і технічне забезпечення для надійного функціонування даного модуля.

Мета дослідження. Забезпечити у комплексі збільшення точності вимірювань, підвищення завадостійкості і зменшення енергоспоживання в контрольно-вимірювальних системах за рахунок ї побудови або модернізації на основі використання універсального вимірювального модуля, який функціонує на основі принципів часового представлення вимірювальної інформації.

\section{Базові принципи функціонування i побудови модуля}

В основі функціонування i побудови запропонованого вимірювального модуля лежить принцип часового представлення вимірювальної інформації. Він передбачає використання модуляції вимірюваною фізичною величиною часової тривалості імпульсного тестового сигналу напруги або струму, яка визначається на наперед визначеному амплітудному рівні такого сигналу перед його подачею на вимірювальну схему і після проходження через схему. Узагальнена структурна схема побудови вимірювального каналу за запропонованим принципом показана на рисунку 1 .

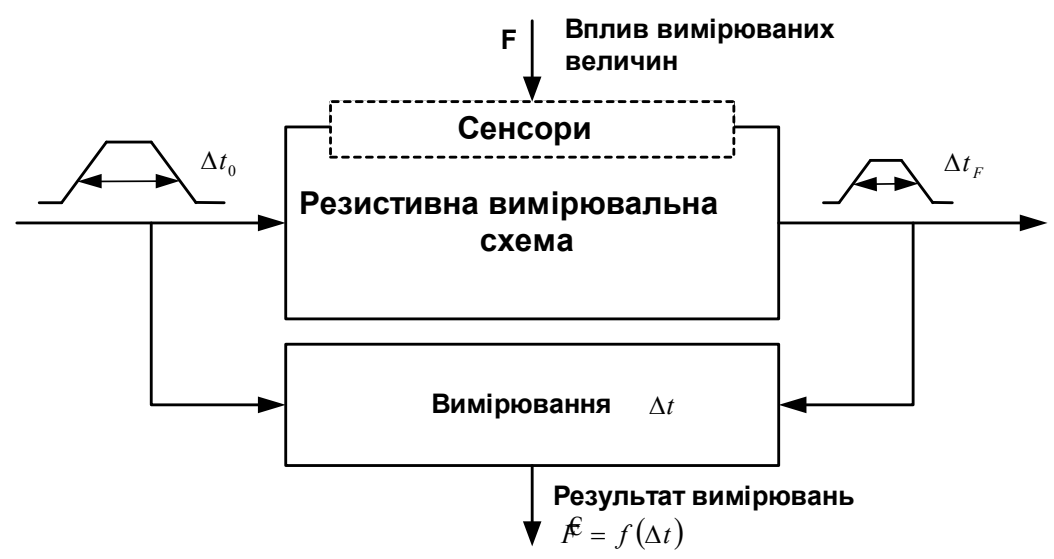

Рис. 1. Узагальнена структурна схема вимірювального каналу з часовим представленням вимірюваної інформації

Відзначені переваги в метрологічних i експлуатаційних характеристиках вимірювальних засобів побудованих на основі використання принципу часового представлення вимірювальної інформації забезпечуються завдяки:

a) переходу в імпульсний режим роботи вимірювальних каналів, причому можливе проведення вимірювань в режимі одиночного імпульсу (зменшення енергоспоживання, підвищення завадостійкості);

б) вимірювання значення фізичної величини зводиться до вимірювання часової тривалості, як відомо $[1,2]$, вимірювання часу сьогодні $\epsilon$ найточнішим серед вимірювань інших фізичних величин (підвищення точності вимірювань). Внаслідок дії вимірюваної фізичної величини на резистивні сенсори вимірювальної схеми разом із зміною амплітуди імпульсних тестових сигналів буде спостерігатися i зміна їх тривалості, вимірювання якої технічно здійснювати простіше i це можливо зі значно більшою точністю. Оцінка значення вимірюваної фізичної величини визначається на основі встановлених математичних залежностей.

В якості тестових сигналів можуть використовуватися імпульсні сигнали, які відповідають критерію однозначності визначення тривалості на заданому рівні. Форма таких сигналів повинна описуватися унімодальними функціями, які $\epsilon$ диференційованими на інтервалах 3 збереженням постійності знаку: $f^{\prime}(U, t) \succ 0$ - на інтервалі зростання, $f^{\prime}(U, t)=0$ - на інтервалі стаціонарності, $f^{\prime}(U, t) \prec 0$ - на інтервалі спадання. Причому у загальному випадку будь-який 3 означених інтервалів може включати в себе лише одну точку. 
Переваги практичного застосування принципу вимірювань, який базується на вимірюваннях зміни тривалості імпульсних сигналів визначаються високою точністю вимірювань часової тривалості імпульсів за допомогою серійних мікросхем часоцифрових перетворювачів (TDC) фірми Acam mess electronic $\mathrm{GmbH}$, абсолютне значення роздільної здатності яких сягає $14 \cdot 10^{-12}$ секунди. Крім того, уніфіковані комунікаційні властивості модуля розраховані на підключення стандартних мостових або потенціометричних вимірювальних схем 3 резистивними сенсорами дозволяють використовувати його для модернізації застарілих вимірювальних систем без їх суттєвої реконструкції. Наднизьке енергоспоживання мікросхем TDS, а також можливість проводити одиночні вимірювання за допомогою одного імпульсу дають можливість будувати високоточні засоби вимірювань 3 автономним живленням і навіть 3 живленням від невеликих за площею фотоелектричних перетворювачів.

\section{Математичні і метрологічні засади побудови вимірювального модуля}

Виконані дослідження дозволили встановити аналітичні залежності зміни тривалості імпульсних тестових сигналів від зміни їх амплітуди, за умови, що ця тривалість визначається на фіксованому рівні. Також отримані математичні моделі, які визначають чутливість таких залежностей. Результати цих досліджень зведені в таблицю 1.

Аналіз отриманих математичних моделей дозволяє зробити висновок, що для імпульсних сигналів 3 гіперболічною формою фронтів спостерігається лінійна залежність зміни його тривалості від зміни амплітуди, тому у всьому діапазоні вимірювань для даної залежності чутливість буде залишатися постійною. Отже використання даного виду сигналу в запропонованій структурі вимірювального каналу дозволить отримувати високочутливу i лінійну шкалу вимірювань. Приклади типових форм імпульсних тестових сигналів, для яких проводилися дослідження, подані на рисунку 2.

Таблиия 1

Аналітичні залежності зміни тривалості імпульсних тестових сигналів

\begin{tabular}{|c|c|c|c|c|}
\hline $\begin{array}{l}\text { № } \\
\text { 3/ח }\end{array}$ & $\begin{array}{l}\text { Вид форми } \\
\text { ITC }\end{array}$ & $\begin{array}{c}\text { Математична } \\
\text { модель ITC }\end{array}$ & $\begin{array}{c}\text { Функція залежності } \Delta t \\
\text { від амплітуди ITC }\end{array}$ & $\begin{array}{c}\text { Чутливість отриманої } \\
\text { залежності }\end{array}$ \\
\hline 1 & Пилкоподібна & $\begin{array}{l}U(t)=U_{\max } \frac{t}{t_{i}} ; \forall t \in\left[0, t_{i}\right] \\
U(t)=0 ; 0>t>t_{i}\end{array}$ & $\Delta t=t_{i}\left(1-\frac{L}{U_{m}}\right)$ & $S_{m}=\frac{\partial \Delta t}{\partial U_{m}}=\frac{t_{i} L}{U_{m}^{2}}$ \\
\hline 2 & $\begin{array}{l}\text { Трикутна } \\
\text { (симетрична) }\end{array}$ & $\begin{array}{l}U(t)=\frac{U_{m}}{t_{b}}\left(t+2\left(t-t_{6}\right) 1\left(t-t_{B}\right)+\right. \\
+\left(t-t_{i}\right) 1\left(t-t_{i}\right)\end{array}$ & $\begin{array}{l}\Delta t=2 \Delta t_{\text {пилк. }}= \\
2 t_{B}\left(1-\frac{L}{U_{m}}\right)\end{array}$ & $S_{m}=\frac{\partial \Delta t}{\partial U_{m}}=2 \frac{t_{\theta} L}{U_{m}^{2}}$ \\
\hline 3 & $\begin{array}{l}\text { Трапецієподібна } \\
k \text { - коефіцієнт } \\
\text { с - коефіцієнт }\end{array}$ & $\begin{array}{l}U(t)=k \cdot t-k \cdot\left(t-t_{f 1}\right) \cdot 1\left(t-t_{f 1}\right)- \\
-c \cdot\left(t-t_{f 2}\right) \cdot 1\left(t-t_{f 2}\right)+ \\
+c \cdot\left(t-t_{i}\right) \cdot 1\left(t-t_{i}\right) \\
\text { (загальна) }\end{array}$ & $\begin{array}{l}\Delta t=\left(t_{f 1}+t_{f 2}\right)\left(1-\frac{L}{U_{m}}\right)+ \\
+t_{f 2}-t_{f 1} \\
\quad \text { (симетрична) }\end{array}$ & $\begin{array}{l}S_{m}=\frac{\partial \Delta t}{\partial U_{m}}= \\
\frac{L}{U_{m}^{2}}\left(t_{f 1}+t_{f 2}\right)\end{array}$ \\
\hline 4 & $\begin{array}{l}\text { Дзвоноподібна } \\
a \text {-коефіцієнт форми }\end{array}$ & $U(t)=U_{m} e^{\frac{-\left(t-t_{v}\right)^{2}}{2 a^{2}}}$ & $\Delta t=2 a \sqrt{2 \ln \left(\frac{U_{m}}{L}\right)}$ & $S_{m}=\frac{a \sqrt{2}}{U_{m} \sqrt{\ln \left(\frac{U_{m}}{L}\right)}}$ \\
\hline 5 & $\begin{array}{l}\text { Експоненційна форма } \\
\text { фронтів } \\
g \text {-коефіцієнт }\end{array}$ & $U(t)=U_{m} e^{-g\left|t_{0}-t\right|}$ & $\Delta t=\frac{2}{g} \ln \left(\frac{U_{m}}{L}\right)$ & $S_{m}=\frac{\partial \Delta t}{\partial U_{m}}=\frac{2}{g U_{m}}$ \\
\hline 6 & $\begin{array}{l}\text { Гіперболічна } \\
\text { форма фронтів } \\
b \text { - коефіцієнт }\end{array}$ & $\left\{\begin{array}{l}U(t)=U_{m} \frac{b}{\left|t-t_{0}\right|} \\
U(t) \leq U_{\max } \forall t \in[0 ;+\infty]\end{array}\right.$ & $\Delta t=\frac{2 b U_{m}}{L}$ & $S_{m}=\frac{2 b}{L}=$ const \\
\hline
\end{tabular}




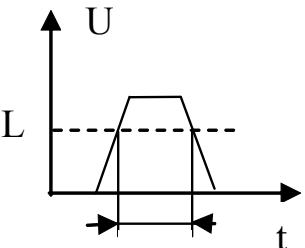

$\Delta t$

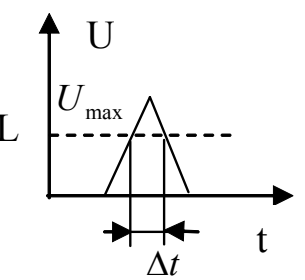

$\mathrm{L}$

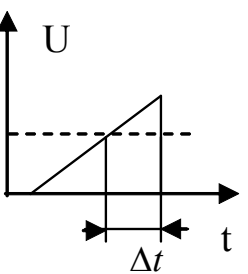

$\mathrm{L}$

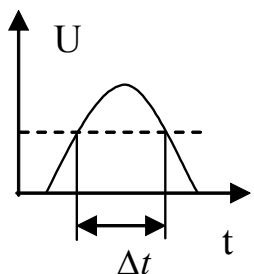

Рис. 2. Приклади типових форм імпульсних тестових сигналів

Основні метрологічні характеристики для потенціометричної вимірювальної схеми при іiі використанні у вимірювальному каналі в поєднані 3 розробленим вимірювальним модулем подані в таблиці 2.
У формулах таблиці використані такі позначення: $R$ - постійний опір вимірювальної схеми; $R_{f}$ - опір сенсора вимірювальної схеми.

Таблиия 2

Основні метрологічні характеристики

\begin{tabular}{|c|c|c|}
\hline Вит hоруи & \multicolumn{2}{|c|}{ Потенціометрична вимірювальна схема } \\
\hline імпульсний тестовий & $\begin{array}{c}\text { Рівняння } \\
\text { перетворення }\end{array}$ & $\begin{array}{c}\text { Чутливість } \\
\text { перетворення } \\
S_{R}\end{array}$ \\
\hline Пилкоподібний & $\Delta_{\text {bux }}=\Delta t_{B x .}-\frac{R\left(t_{i}-\Delta_{B x}\right)}{R_{f}(t)}$ & $S_{R}=\frac{\partial \Delta \mathrm{t}_{\text {вих }}}{\partial \mathrm{R}_{\mathrm{f}}}=\frac{R\left(t_{i}-\Delta t_{6 x}\right)}{R_{f}^{2}}$ \\
\hline Дзвоноподібний & & $2 a R$ \\
\hline & $\Delta_{\text {Bux }}=\sqrt{\Delta^{2}{ }_{B x}+4 a^{2} \ln \frac{R_{f}}{R+R_{f}}}$ & $\mathrm{R}_{\mathrm{f}}\left(R+\mathrm{R}_{\mathrm{f}}\right) \sqrt{\Delta \mathrm{t}_{\mathrm{Bx}}^{2}+4 a^{2} \ln \left(\frac{\mathrm{R}_{\mathrm{f}}}{R+\mathrm{R}_{\mathrm{f}}}\right)}$ \\
\hline $\begin{array}{l}\text { Експоненційна форма } \\
\text { фронтів }\end{array}$ & $\Delta_{\text {sux }}=\Delta t_{\text {sx. }}+\frac{2}{g} \ln \left(\frac{R_{f}}{R+R_{f}}\right)$ & $2 \frac{R}{g R_{f}\left(R+R_{f}\right)}$ \\
\hline $\begin{array}{l}\text { Гіперболічна } \\
\text { форма фронтів }\end{array}$ & $\Delta_{B u x}=\Delta t_{B x .} \frac{R_{f}}{R+R_{f}}$ & $\Delta \mathrm{t}_{\mathrm{Bx}} \frac{R}{\left(R+R_{f}\right)^{2}}$ \\
\hline
\end{tabular}

\section{Структурна і функціональна схеми вимірювального модуля}

Розроблені математичні і метрологічні засади побудови вимірювального модуля в поєднані 3 можливостями спеціалізованої елементної бази (TDC) дозволили запропонувати уніфіковану структурну схему вимірювального каналу, яка показана на рисунку 3.

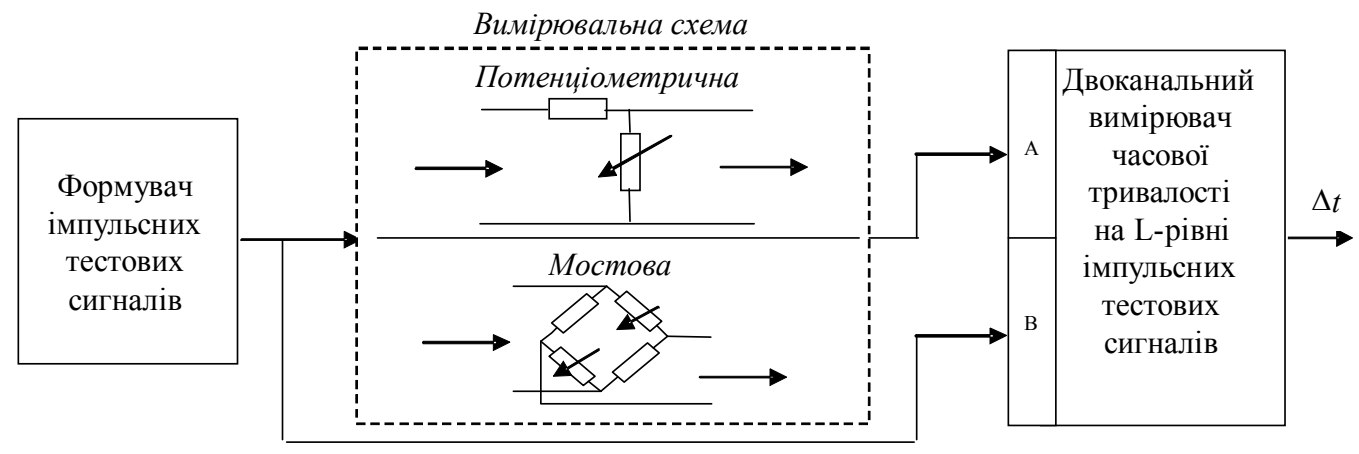

Рис. 3. Уніфікована структурна схема вимірювального каналу

(C) Ю.В. Шабатура, К.В. Овчинников, Ю.В. Бугайов 
Практична реалізація вимірювального модуля виконана на основі мікросхеми часо-цифрового перетворювача PS021 фірми Acam mess electronic $\mathrm{GmbH}$ в складі якого містяться необхідні засоби для спряження перетворювача 3 зовнішніми пристроями та вимірювальними колами. Точність вимірювання часових інтервалів таким перетворювачем в штатному режимі - 60 пікосекунд. Наявність двох незалежних каналів вимірювання в даному перетворювачі дозволяє одночасно обслуговувати два вимірювальних моста компенсаторного або не компенсаторного типу, або чотири напівмоста без втрати точності. Також цей перетворювач виконує окреме вимірювання температури для корекції результату вимірювання у відповідності до зовнішніх умов. Для спряження 3 зовнішніми пристроями у складі перетворювача міститься апаратний послідовний інтерфейс сумісний з SPI (послідовний периферійний інтерфейс).
Оскільки такий інтерфейс не придатний для застосування у промислових умовах, а призначений виключно для застосування на невеликих відстанях і в умовах незначної дії завад, тому вимірювальний модуль на основі часо-цифрового перетворювача необхідно додатково забезпечити засобами для спряження із зовнішніми пристроями. 3 цією метою до складу вимірювального модуля введено мікроконтролер, який виконуватиме функції керування часо-цифровим перетворювачем та спряження 3 зовнішніми пристроями. В базовому варіанті сучасний мікроконтролер має апаратний інтерфейс RS-232, а при потребі і відповідному апаратному та програмному забазпеченні можна реалізувати інші інтерфейси: RS-485, USB, CAN, тощо.

На рисунку 4 наведена функціональна схема розробленого вимірювального модуля.

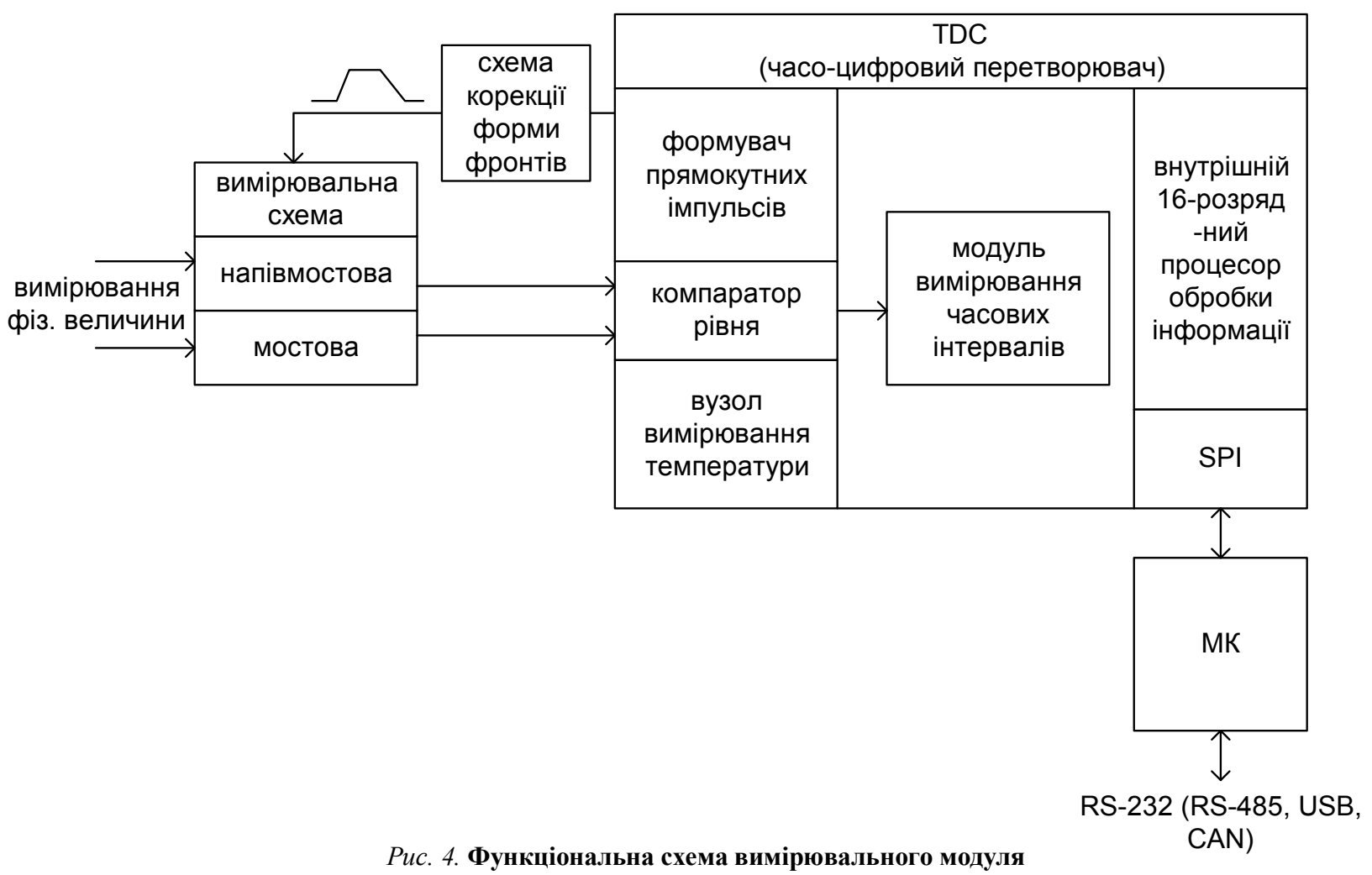

\section{Алгоритмічне забезпечення}

В розробленому модулі процесом вимірювання керує мікроконтроллер. Він виступає в якості ініціатора вимірювального циклу, який може складатися 3 одиничного вимірювання або 3 послідовності вимірювань, 3 подальшим обробленням накопичених даних.

(C) Ю.В. Шабатура, К.В. Овчинников, Ю.В. Бугайов
У випадку одиночного вимірювання контролер подає команду почати вимірювання і по закінченню процедури вимірювання вилучає результат з регістрів часо-цифрового перетворювача. Отриманий результат передається по зовнішньому інтерфейсу на вищій рівень. Такий принцип побудови алгоритму роботи вимірювального модуля забезпечує високу швидкодію процесу вимірювання але не забезпечує необхідний рівень стійкості до короткочасних завад. 
Тому модуль може функціонувати також в режимі послідовних вимірювань 3 подальшим обробленням результатів. Один з варіантів побудови алгоритму неперервного вимірювання полягає у наступному: контролер ініціює процес неперервного вимірювання в процесі якого поступово накопичує результати вимірювань. По завершені визначеного числа вимірювань контролер зупиняє процес вимірювання і починає обробку накопичених даних. В залежності від вимог, що висуваються до вимірювального модуля обробка даних може бути обмежена найпростішим усередненням результатів вимірювань або більш складним процесом фільтрації iз застосуванням методів цифрової обробки даних. Такій підхід дозволяе отримати на виході результат вимірювань інваріантний до дії завад, однак при цьому збільшується час вимірювання.

Компромісним варіантом побудови алгоритму роботи $\epsilon$ режим безперервного вимірювання при якому процес вимірювання не зупиняється, а обробка результатів вимірювання відбувається ітераційно, в реальному масштабі часу. Єдиним недоліком такого підходу є необхідність застосування мікроконтролера 3 високою швидкодією, але на сучасному етапі розвитку обчислювальної техніки використання надпотужних контролерів у вбудованій техніці стає звичайною справою.

\section{Висновки}

В статті розглянуті основні принципи побудови універсального вимірювального модуля на основі часового представлення інформації 3 використанням часо-цифрового перетворювача. Розроблені математичні, метрологічні, технічні і алгоритмічні засади для створення такого модуля.

\section{Список літератури}

1. Дьяченко К.П. Электрические измерения. Средства и методы измерений / К.П. Дьяченко, Д.И. Зорин, П.И. Новиикий и др.; под общ. ред. Е.Г. Шрамкова. - М.: Высш. Школа, 1972. - 520 с.

2. Туричин А.М. Электрические измерения неэлектрических величин / А.М. Туричин, П.В. Новицкий, Е.С. Левшина и др.; под общ. ред. П.В. Новичкого. - Л.: Энергия, 1975. - $576 c$.

3. Полішук С.С.Методи та засоби вимірювань неелектричних величин / С.С. Поліщук. - Львів: «Львівська політехніка», 2000. $-360 \mathrm{c}$.

4. Кожемяко В.П. Оптоэлектронные логиковременные информачионно-вычислительные среды / В.П. Кожемяко. - Тбилиси: Мецниереба, 1984. - 360 с.

5. Шабатура Ю.В. Основи теорії і практики інтервальних вимірювань: моногр. / Ю.В. Шабатура. Вінниия: УНІВЕРСУМ-Вінниия, 2003. - 167 c.

Надійшла до редакиії 10.09.2009 р.

\title{
УНИВЕРСАЛЬНЫЙ ИЗМЕРИТЕЛЬНЫЙ МОДУЛЬ ДЛЯ ПОСТРОЕНИЯ И МОДЕРНИЗАЦИИ КОНТРОЛЬНО-ИЗМЕРИТЕЛЬНЫХ СИСТЕМ ВОЕННО-ТЕХНИЧЕСКИХ КОМПЛЕКСОВ
}

\author{
Ю.В. Шабатура, К.В. Овчинников, Ю.В. Бугайов
}

Выполнена разработка математического, метрологического, технического, и алгоритмического обеспечения для построения универсального измерительного модуля, который функционрует на основе использования принципа временного представления измерительной информации. Проведенные исследования показали пригодность разработанного модуля не только для построения новых средств измерения но и для модернизации устаревших измерительных приборов и систем. Применение модуля позволяет существенно увеличить точность измерений и помехоустойчивость с одновременным уменьшением энергопотребления.

Ключевые слова: импульсные тестове сигналь временное представление измерительной информации, времяичировые преобразователи, мостовая, потенииометрическая измерительная схема.

\section{THE UNIVERSAL MEASURING MODULE FOR CONSTRUCTION AND MODERNIZATION OF CONTROL AND MEASURING SYSTEMS OF MILITARY-TECHNICAL COMPLEX}

\author{
Y.V. Shabatura, K.V. Ovchinnikov, Y.V. Bugayov
}

Design of mathematical, metrological, technical and algorithmic maintenance for construction of the universal measuring module which functions on the basis of use of a principle of time representation of the measuring information is executed. The conducted researches have shown the validity of the developed module not only for construction of new gauges but also for modernization of out-of-date measuring devices and systems. Module use allows raising essentially accuracy of measurements and noise stability with simultaneous reduction of power consumption.

Keywords: tests impetus signals, time representation of measurement information, time to digital converters, bridge, potentiometric measurement circuit. 